\title{
Article
}

\section{Effect of Systems to Manage Environmental Aspects on Environmental Performance}

\section{Dietrich Earnhart}

Department of Economics, University of Kansas, 435 Snow Hall, Lawrence, KS 66045, USA; E-Mail: Earnhart@ku.edu; Tel.: +1-785-864-2866

Received: 25 March 2013; in revised form: 28 May 2013 / Accepted: 30 May 2013 /

Published: 7 June 2013

\begin{abstract}
This paper analyzes the effect of systems to manage environmental aspects on environmental performance at individual polluting facilities. Regulated polluting facilities are increasingly embracing pollution minimization strategies that involve the adoption of broadly defined systems to manage environmental aspects. Despite a meaningful empirical literature, whether or not these systems lead to better environmental performance remains an open question. This study seeks to assess the possible connection between systems to manage environmental aspects and improved environmental performance. It also seeks to identify the factors determining the extent of the adopted system of management and the factors' direct effects on environmental performance. For this empirical analysis, the study examines the extent of systems to manage environmental aspects employed by and the level of wastewater discharged by U.S. chemical manufacturing facilities during 2001.
\end{abstract}

Keywords: environmental; management; performance; compliance; wastewater; discharges; chemical manufacturing

\section{Introduction}

Historically, the pollution control efforts expended by regulated industrial facilities have focused on the installation and operation of end-of-pipe treatment technologies. However, as environmental protection efforts have matured, environmental protection agencies have begun to explicitly promote the use of pollution prevention management approaches that frequently involve the design and implementation of informal and formal environmental management systems (EMSs). For example, the European Union (EU) promotes its Eco-Management and Audit Scheme (EMAS) program for certifying EMSs. Woven into this trend are "business-led" initiatives that promote participation in 
trade association programs emphasizing environmental management codes, such as the Responsible Care program of the American Chemistry Council, or the adoption of international certification standards for environmental management, such as the International Organization of Standards (ISO) 14001 program. This increasing use of preventive management approaches and business-led initiatives represents an important institutional change in corporate culture and management practices [1].

Both the U.S. Environmental Protection Agency (EPA) and U.S. state environmental protection agencies have expressed their interest in learning more about this increasing use of preventive environmental management approaches. More importantly, these agencies have created government programs to encourage the adoption of these environmental management systems. These government programs offer technical assistance, recognition, financial benefits, and regulatory benefits to facilities that employ an environmental management system [2]. These programs presumably promote the adoption of EMSs because the policymakers believe that the implementation of an EMS will lead to improved environmental performance.

However, this connection is still being assessed empirically. As of yet, no strong empirical conclusion has been drawn. Some previous studies examining the effect of environmental management practices on environmental performance provide evidence supporting a positive link from systems of management to environmental performance [1,3-5]. However, other empirical studies provide incomplete evidence or no evidence supporting a positive link [6-9]. (Two possible reasons for the lack of a positive link involving certified EMSs are offered by Andrews et al. [10]. First, a facility with strong environmental performance implements a certified EMS yet retains its existing management methods while adding no new practices. Second, a facility with weak environmental performance implements a certified EMS merely to satisfy external demands, such as those from consumers, or to strengthen its corporate image, while failing to commit to stronger environmental stewardship).

Similar to these previous empirical studies, the current study seeks to assess the possible connection between systems to manage environmental aspects and environmental performance. Specifically, this study empirically analyzes the effect of systems to manage environmental aspects on the level of environmental performance at water polluting facilities, in particular, wastewater discharges by US chemical manufacturing facilities during 2001. The study measures environmental performance by the ratio of absolute discharges to effluent limits-relative discharges, i.e., extent of compliance, which captures both the degree of non-compliance and over-compliance. For this calculation, the study considers all regulated water pollutants. Specifically, the study examines the ratio of absolute discharges and effluent limit for each pollutant identified in a particular facility's permit. Thus, the study focuses exclusively on quantitative environmental performance; in this regard, the study ignores intangible improvements in environmental performance, e.g., better compliance management, better emergencies management, increase of workers' awareness. The study measures the extent of an environmental management system in various dimensions, such as the frequency of auditing, the communication of management's environmental compliance targets to plant staff, and the role of general employees in identifying and correcting potential non-compliance issues.

Given the voluntary nature of adopting systems to manage environmental aspects, facilities possess substantial flexibility over which dimensions to incorporate into the adopted system. And within any given dimension, facilities have considerable flexibility over the degree of implementation. For example, facilities may choose to audit on a quarterly basis or on a monthly basis. Analysis of the 
surveyed sample of facilities reveals substantial variation across facilities in both regards: number of dimensions adopted and the degree of adoption within a given dimension. With this variation in mind, the study also seeks to identify the factors determining the extent of the adopted system to manage environmental aspects, with a focus on regulatory pressure as applied through the use of inspections and sanctions.

When examining the level of environmental performance, this study also examines the direct effects of these same factors on environmental performance, as opposed to the indirect effects via the influence of the system to manage environmental aspects on environmental performance.

Our study contributes to a rich empirical literature on environmental behavior and performance. To clarify the distinction, environmental behavior includes environmental management practices, e.g., self-audits, along with other forms of pollution control efforts, such as the use of end-of-pipe treatment technologies. In contrast, environmental performance includes wastewater discharges, along with other forms of pollution outcomes, such as air pollutant emissions and toxic/hazardous waste generation.

Several empirical studies examine environmental behavior without assessing its influence on environmental performance. As two examples, Harrington et al. [11] examine the motivations prompting the adoption of Total Quality Environmental Management (TQEM), while Khanna et al. [12] examine the link from TQEM to the implementation of pollution prevention practices. Other empirical studies examine environmental performance without assessing the role of environmental behavior [13,14]. In this literature review, we focus on empirical studies examining the effect of environmental behavior, especially environmental management practices, on environmental performance. Anton et al. [1] examine the influence of the comprehensiveness of a firm's environmental management system, as measured by the count of adopted environmental management practices, on four measures of a firm's toxic emissions per unit of output; the study demonstrates that the extent of EMS adoption has a significant negative impact on the intensity of toxic emissions. Barla [6] examines the influence of ISO 14001 certification on wastewater discharges from Quebec pulp and paper plants. The study tests whether adopting an ISO 14001-certified environmental management system affects environmental performance; results reveal that adoption decreases BOD discharges but not TSS discharges. Arimura et al. [3] explore the effect of ISO 14001 implementation and environmental reporting on Japanese facilities' environmental performance as measured by natural resource use, solid waste generation, and wastewater discharge; results demonstrate that both ISO 14001 implementation and environmental reporting reduce all three impacts. Gangadharan [15] examines the influence of environmental training on Mexican plants' environmental compliance. Sam et al. [16] analyzes the adoption of Total Quality Environmental Management (TQEM) and releases of pollutants covered by the EPA 33/50 Program; they find that TQEM adoption reduces 33/50 releases and that its effect is distinct from the effect of participation in the 33/50 Program. Daddi et al. [4] reveal that adoption of an EMAS-certified environmental management system leads to an improvement in environmental performance as measured by water consumption, electric energy consumption, total energy consumption, and waste production. Johnstone et al. [17] find that ISO 14001 certification and EMAS certification appear effective at improving firms' environmental performance in a number of areas, with this positive impact particularly important in the areas of wastewater discharges and air pollutant emissions. Potoski and Prakash [18] find some evidence that ISO 14001-certified U.S. companies reduce their toxic emissions more quickly than non-certified companies. Iraldo et al. [19] assess 
whether or not EMAS certification of an EMS improves corporate environmental performance using a sample of companies interviewed as part of the EU Evaluation of EMAS for its Revision (EVER) project; they find a positive link from a well-designed EMS to environmental performance as measured by the companies' reported perceptions of environmental performance. King et al. [20] provide evidence that adoption of an ISO 14001-certified EMS leads to improved environmental performance as measured by the toxicity-weighted sum of toxic emissions. Hertin et al. [8] conduct regression analysis and time series analysis in order to explore the links between a company's EMS and corporate environmental performance, as measured by eco-efficiency indicators, using data on European industrial companies; their results reveal that the overall link is weak and ambiguous: companies with a formal EMS perform better based on some eco-efficiency indicators, yet worse on several other indicators, with only a small number of links proving statistical significant. Similarly, Hertin et al. [9] assess whether the presence of an EMS positively affects European companies' eco-efficiency using measures such as air pollutant emissions, municipal waste, recycled waste, hazardous waste, and energy input (all scaled by production levels); their study reveals no evidence that an EMS has a consistent and significantly positive impact on corporate environmental performance. (Two studies explore the effects of ISO 14001 certification and EMS certification on environmental innovation, which is generally not regarded as a measure of environmental performance $[21,22]$.)

As more relevant research, three empirical studies examine the effect of environmental management system adoption on compliance with environmental regulations. First, Dasgupta et al. [5] examine the influence of a Mexican company's environmental management system and provision of environmental training on the company's environmental compliance status. The study finds that the adoption of an ISO 14001-certified environmental management system leads to a significant improvement in compliance status. It also reveals that environmental training provided to non-environmental workers, as well as environmental workers, improves the self-reported degree of compliance. Second, Potoski and Prakash [23] examine the factors that drive ISO 14001 participation among U.S. facilities and the effects of participation on compliance with Clean Air Act regulations. Their results reveal that ISO 14001 participation increases Clean Air Act compliance. Third, Sam [24] analyzes the effects of environmental management system adoption, along with other pollution prevention activities, on overall environmental compliance; his findings reveal that environmental management system adoption increases compliance during the early 1990s within the sample period of 1991-2004. Fourth, Evans et al. [25] and Khanna and Widyawati [26] examine the influence of environmental self-audits on environmental compliance. Evans et al. [25] examine the effect of auditing, as measured by the filing of an intent to conduct an audit, on Michigan facilities' compliance with the Resource Conservation and Recovery Act (RCRA). Their results suggest no long-run impact of auditing on compliance with hazardous waste regulations. Khanna and Widyawati [26] explore the effect of firm-wide environmental auditing programs on facility-level compliance with Clean Air Act regulations using a sample of S\&P 500 firms. Their results demonstrate that facilities owned by firms that reported an environmental audit in the Investor Research Responsibility Center (IRRC) survey are significantly more likely to be compliant with Clean Air Act regulations. Fifth, Dahlström et al. [7] reveal that neither ISO 14001 nor EMAS certification has a positive effect on United Kingdom companies' compliance with environmental regulations (as captured by a regulator's assessment of the 
likelihood of incidents, complaints, or non-compliance events); however, their results reveal a positive link from EMS certification to better procedural performance.

The current study contributes to the literature in two major ways. As the primary contribution, this study explores the effect of environmental management on the extent of compliance. Thus, the results are able to speak equally to success at achieving compliance and "going beyond compliance". As the secondary contribution, this study explores the extent of environmental management adoption when assessing management's effect on environmental performance. Most previous studies examine only the dichotomous choice to implement or not implement a particular management practice or set of practices. Few studies examine the chosen extent of environmental management adoption [1,5,27].

\section{Data}

To examine empirically the influence of systems to manage environmental aspects on environmental performance, this study gathers data from two main sources. First, data on environmental management practices employed by individual facilities, as well as data on the characteristics of these facilities and the firms that own these facilities, come from an original survey of US chemical manufacturing facilities. Second, data on environmental performance come from the EPA Permit Compliance System (PCS) database.

\subsection{Survey of Chemical Facilities}

\subsubsection{Survey Implementation}

To implement the survey of chemical manufacturing facilities, the study first identified the proper population of facilities to survey. The population is based on a full extract drawn from the EPA's PCS database as of September, 2001. This extract includes 2,596 chemical facilities. To remain in the survey population, facilities needed to meet the following criteria: (1) possessed a wastewater discharge permit; (2) faced restrictions on their wastewater discharges, (3) discharged regulated pollutants into surface water bodies, and (4) were operating as of 2002.

In order to focus on discharges into surface water, the study eliminated 984 facilities from the sample because they were either (1) industrial users, i.e., discharge into pre-treatment programs run by publicly-owned treatment works [POTWs]; (2) facilities using general permits (e.g., gravel pits); (3) facilities discharging only bio-solids (i.e., sludge); and/or (4) facilities discharging only storm water. The study eliminated industrial users because their discharges are monitored by the POTWs into which facilities discharge. The study chose to focus on the direct relationship between state/federal regulators and regulated facilities. The study eliminated facilities possessing only general permits because this type of permit involves distinctively different restrictions. By eliminating those facilities discharging only sludge or only stormwater, the analysis is better able to examine a sufficiently comparable set of environmental management concerns.

After excluding the facilities that did not meet the relevant criteria, the study identified 1,003 facilities to contact. Of those facilities contacted between April of 2002 and March of 2003, 735 refused to participate in the survey. Respondents from the remaining 268 facilities completed at least 90 percent of the survey, implying a survey response rate of $27 \%$. This rate is comparable to 
recently published large-scale surveys of industrial sectors [3] and lies above the average response rate of $21 \%$ for business surveys used by studies published in academic journals [28].

Within the National Pollutant Discharge Elimination System (NPDES), which represents the EPA's implementation of the Clean Water Act (CWA) as it relates to point sources of wastewater pollutant discharges, the EPA classifies facilities as either "major facilities" or "minor facilities". For the classification of each regulated facility, the EPA calculates a major rating with points assigned on the basis of toxic pollution potential, flow type, conventional pollutant load, public health impact, and water quality impact; the EPA classifies any discharger with a point total of 80 or more as a "major facility". The survey contacted both major and minor facilities. Based on empirical analysis of all survey recipients, the study tests for sample selection bias using the Heckman two-stage sample selection technique [29]. This testing reveals that major facilities were more likely to respond to the survey than minors, otherwise, survey respondents and survey non-respondents do not differ based on observable measures. (The appendix describes this testing and other forms of sample selection bias assessment.) As described below, the analysis of environmental performance generated by survey respondents applies only to major facilities due to limitations on publicly available data on effluent limits and discharge measurements. Therefore, the need for sample selection correction does not seem warranted. Moreover, the appendix reveals that within the category of major facilities, environmental performance does not differ statistically between survey respondents and non-respondents. For both reasons, the study does not correct for any potential sample selection bias. This lack of correction is consistent with recent prominently published studies of environmental management practices [1,3].

\subsubsection{Survey Data on Environmental Management}

The survey of chemical manufacturing facilities gathers specific information on the environmental management practices of individual chemical manufacturing facilities. The survey specifically gathers information on the facility employees allocated to ensure facility compliance with environmental regulations, environmental training programs, environmental consulting expenditures, upgrades performed on wastewater treatment equipment, the stringency of protocols to monitor the treatment process and upstream sewer wastewater flow, ISO 14001 compliance, self-audit programs, internal and external environmental communications, and the role of general facility employees in environmental issues. (This study interprets upgrades performed on wastewater treatment equipment as an environmental management practice broadly defined. Clearly, these upgrades more likely represent end-of-pipe treatment. Thus, the chosen interpretation of upgrades may alter the separation between end-of-pipe treatment and environmental management in our analysis.) Table 1 summarizes the reported data on environmental management practices. 
Table 1. Measures of Environmental Management.

Table 1a. Qualitative Measures.

\begin{tabular}{|c|c|c|c|}
\hline Measure & Category & $\begin{array}{c}\% \text { of } \\
\text { Facilities }\end{array}$ & $\begin{array}{c}\text { Ordinal, } \\
\text { Binary } \\
\text { Rank }\end{array}$ \\
\hline \multirow{4}{*}{$\begin{array}{l}\text { Type of Training Program for } \\
\text { Environmental Employees }\end{array}$} & None & 7 & 1 \\
\hline & Internal (in-house) only & 30 & 2 \\
\hline & External only & 31 & 3 \\
\hline & Both internal and external & 32 & 4 \\
\hline \multirow{2}{*}{$\begin{array}{l}\text { Use of External Consultants for } \\
\text { Wastewater }\end{array}$} & No & 32 & 0 \\
\hline & Yes & 68 & 1 \\
\hline \multirow{2}{*}{$\begin{array}{l}\text { Wastewater Treatment Upgrade } \\
\text { performed between } 1999 \text { and } 2001\end{array}$} & No & 39 & 0 \\
\hline & Yes & 61 & 1 \\
\hline \multirow{2}{*}{$\begin{array}{l}\text { If Upgrade Performed, Intent to } \\
\text { Reduce Pollutant Discharges }\end{array}$} & No & 25 & 0 \\
\hline & Yes & 75 & 1 \\
\hline \multirow{4}{*}{$\begin{array}{l}\text { Stringency of Wastewater Process and } \\
\text { Sewer Monitoring }\end{array}$} & Effluent monitoring only & 21 & 1 \\
\hline & Effluent + process monitoring & 15 & 2 \\
\hline & $\begin{array}{l}\text { Effluent }+ \text { process }+ \text { single point sewer } \\
\text { monitoring }\end{array}$ & 28 & 3 \\
\hline & $\begin{array}{l}\text { Effluent }+ \text { process }+ \text { multiple point sewer } \\
\text { monitoring }\end{array}$ & 36 & 4 \\
\hline \multirow[t]{2}{*}{ ISO 14001 Compliance } & No & 88 & 0 \\
\hline & Yes & 12 & 1 \\
\hline \multirow[t]{4}{*}{ Audit Team Composition } & No audits conducted & 4 & 1 \\
\hline & Facility employees only & 27 & 2 \\
\hline & Visiting corporate/consultants only & 14 & 3 \\
\hline & Both facility and corporate/consultants & 55 & 4 \\
\hline \multirow[t]{4}{*}{ Audit Findings Classification Protocol } & Only non-compliance findings noted & 25 & 1 \\
\hline & 2 categories: non-compliance and other & 30 & 2 \\
\hline & Findings placed into priority categories & 28 & 3 \\
\hline & Findings serially ranked for non-compliance risk & 17 & 4 \\
\hline \multirow{2}{*}{$\begin{array}{l}\text { Assistance Requested from Regulator } \\
\text { on Ways to Reduce Discharges }\end{array}$} & No & 76 & 0 \\
\hline & Yes & 24 & 1 \\
\hline \multirow{6}{*}{$\begin{array}{l}\text { Communication: Environmental } \\
\text { Performance Goals to Employees } \\
\text { [note all that apply] }\end{array}$} & Regularly scheduled meetings/ briefings & 62 & $\mathrm{n} / \mathrm{a}$ \\
\hline & Regular memorandum, newsletter, or email & 48 & $\mathrm{n} / \mathrm{a}$ \\
\hline & Public display board & 38 & $\mathrm{n} / \mathrm{a}$ \\
\hline & General worker training or orientation & 72 & $\mathrm{n} / \mathrm{a}$ \\
\hline & Review item for design or construction projects & 60 & $\mathrm{n} / \mathrm{a}$ \\
\hline & Other & 12 & $\mathrm{n} / \mathrm{a}$ \\
\hline \multirow{6}{*}{$\begin{array}{l}\text { Communication: Environmental } \\
\text { Performance Goals to External Parties } \\
\text { [note all that apply] }\end{array}$} & Press releases & 28 & $\mathrm{n} / \mathrm{a}$ \\
\hline & Advertising & 11 & $\mathrm{n} / \mathrm{a}$ \\
\hline & Open house & 41 & $\mathrm{n} / \mathrm{a}$ \\
\hline & Focus groups & 32 & $\mathrm{n} / \mathrm{a}$ \\
\hline & Websites or internet messages & 34 & $\mathrm{n} / \mathrm{a}$ \\
\hline & Other & 20 & $\mathrm{n} / \mathrm{a}$ \\
\hline
\end{tabular}


Table 1a. Cont.

\begin{tabular}{|c|c|c|c|}
\hline Measure & Category & $\begin{array}{c}\text { \% of } \\
\text { Facilities }\end{array}$ & $\begin{array}{c}\text { Ordinal, } \\
\text { Binary } \\
\text { Rank }\end{array}$ \\
\hline \multirow{4}{*}{$\begin{array}{l}\text { Role of General Employees in } \\
\text { Identifying and Correcting } \\
\text { Conditions that may lead to Non- } \\
\text { Compliance }\end{array}$} & Not important & 1 & 1 \\
\hline & Somewhat important & 8 & 2 \\
\hline & Important & 22 & 3 \\
\hline & Very important & 69 & 4 \\
\hline \multirow{4}{*}{$\begin{array}{l}\text { Role of General Employees in } \\
\text { Identifying Ways to Prevent or } \\
\text { Minimize the Facility's Level of } \\
\text { Wastewater Pollutants }\end{array}$} & Not important & 2 & 1 \\
\hline & Somewhat important & 10 & 2 \\
\hline & Important & 30 & 3 \\
\hline & Very important & 58 & 4 \\
\hline \multirow{4}{*}{$\begin{array}{l}\text { Compliance Assistance Materials } \\
\text { Meet Facilities' Needs: Frequency }\end{array}$} & Never & 0 & 1 \\
\hline & Some of the time & 18 & 2 \\
\hline & Most of the time & 51 & 3 \\
\hline & Always & 31 & 4 \\
\hline
\end{tabular}

Table 1b. Quantitative Measures.

\begin{tabular}{lcc}
\hline \multicolumn{1}{c}{ Measure } & Median & $\begin{array}{c}\text { Standard } \\
\text { Deviation }\end{array}$ \\
\hline Facility Environmental Employees (person-months) in 1999 & 24 & 80 \\
Facility Environmental Employees (person-months) in 2000 & 24 & 76 \\
Facility Environmental Employees (person-months) in 2001 & 20 & 78 \\
Percent of Environmental Employees with College Education (\%) & 75 & 39.3 \\
Average Number of Years of Experience for Environmental Employees (years) & 12 & 6.13 \\
Annual Days of Training for Environmental Employees (days) & 5 & 23.1 \\
Percent of Environmental Employees Attending Training (\%) & 100 & 23 \\
Number of Facility Wastewater Employees (count) & 4 & 17.1 \\
Annual Expenditures on Wastewater Consultants (\$) & 10,000 & 62,045 \\
\hline
\end{tabular}

Table 1c. Distribution of Annual Audit Counts.

\begin{tabular}{ccc}
\hline Audit Count & Percent & Cumulative Percent \\
\hline 0 & 13.89 & 13.89 \\
1 & 39.38 & 53.27 \\
2 & 11.44 & 64.71 \\
3 & 2.94 & 67.65 \\
4 & 10.95 & 78.59 \\
5 & 1.96 & 80.56 \\
6 & 0.98 & 81.54 \\
8 & 0.49 & 82.03 \\
10 & 0.16 & 82.19 \\
12 & 10.46 & 92.65 \\
13 & 0.16 & 92.81 \\
17 & 0.33 & 93.14 \\
20 & 0.33 & 93.46 \\
\hline
\end{tabular}


Table 1c. Cont.

\begin{tabular}{ccc}
\hline Audit Count & Percent & Cumulative Percent \\
\hline 24 & 1.14 & 94.61 \\
27 & 0.16 & 94.77 \\
36 & 0.49 & 95.26 \\
40 & 0.65 & 95.92 \\
45 & 0.65 & 96.57 \\
50 & 0.65 & 97.22 \\
52 & 2.78 & 100.00 \\
\hline
\end{tabular}

The median work effort of facility environmental employees associated with ensuring compliance with environmental regulations is 20 to 24 person-months or 1.7 to 2.0 full-time equivalents (FTE) depending on the year of the sample. The total work effort reported by survey respondents includes full-time employees and part-time employees, and could include operators, maintenance staff, clerical staff, and professional staff. This value is reasonable for a small-to-medium size manufacturing facility.

The median fraction of facility environmental employees with a college education is $75 \%$. Typical operators and engineering staff in the chemical manufacturing environment or in a regulatory compliance role generally require a rigorous technical background consistent with an associate degree or college degree in the sciences or engineering. The median experience level is 12 years.

A training program is provided to environmental employees for $94 \%$ of the surveyed facilities. The median annual days of training is 5 days. Approximately $83 \%$ of the facilities indicate that $100 \%$ of environmental employees attend the training provided by the facility.

Facilities utilize external consultants for wastewater issues to a varying degree. A majority of facilities $(68 \%)$ use external consultants to address wastewater issues. The median annual expenditure for external wastewater consultants by a facility is $\$ 10,000$.

Wastewater treatment plant upgrades were performed in the 1999 to 2001 timeframe at a majority of the facilities (68\%). The wastewater treatment plant upgrades performed are reported by $75 \%$ of the facilities to reduce the level of pollutant discharges.

Facilities utilize varying degrees of process and upstream sewer monitoring. At the lower end, 21\% of facilities monitor only their effluent. At the upper end, $36 \%$ of facilities additionally monitor their treatment process and sewer wastewater flows at multiple points.

ISO 14001 compliance provides an indication of a facility's involvement in industry-wide environmental initiatives. Approximately $12 \%$ of survey respondents are ISO 14001 compliant.

Approximately $96 \%$ of the facilities conduct some form of environmental self-audit. The composition of the audit team may include visiting experts and/or internal employees. At the lower end, $27 \%$ of the facilities employ an audit team that includes only internal employees. At the higher end, 55\% of the facilities employ an audit team that includes both internal employees and external agents (e.g., corporate employees, outside consultants). In between, $14 \%$ of the facilities employ an audit team that includes only external agents. The study regards the involvement of external agents as more important than the involvement of in-house staff.

Table 1c tabulates the distribution of self-audits conducted over a given calendar year by a particular facility. The tabulation reveals that nearly $86 \%$ of the sample facilities conduct at least one 
audit per year; thus, only $14 \%$ of the facilities lack an audit program. The median facility performs a single audit per year. One to three environmental self-audits per year are conducted by a majority of the facilities (54\%). Wastewater compliance is typically assessed monthly via submission of a monthly discharge monitoring report to a regulatory authority; a good portion of facilities (10\%) perform self-audits at a frequency identical to this compliance reporting activity.

The audit classification protocol used by chemical facilities ranges from simple to elaborate, as shown in Table 1a. The lowest level of findings classification includes only the noting of non-compliance findings; $25 \%$ of the facilities conduct this basic classification. In contrast, $45 \%$ of the facilities rank audit findings based on some type of priority scale.

Facilities use a wide variety of methods to communicate environmental performance goals to employees and external parties, as shown in Table 1a. Methods used to communicate environmental goals to general plant employees include regularly scheduled meetings or briefings, memoranda, newsletters, electronic mail, public display boards, general worker orientation, training sessions, or review items for design/construction projects. Methods used to communicate environmental goals to external parties include press releases, advertising, open houses, community focus groups, and websites or electronic mail.

Facilities indicate that the general employee plays a very important role in identifying and correcting conditions that may lead to non-compliance (69\%) and minimizing pollutants (58\%), as indicated in Table 1a. Only a small fraction of facilities indicate that the general plant employee plays an unimportant or only somewhat important role in identifying and correcting conditions that may lead to non-compliance $(9 \%)$ or minimizing pollutants $(12 \%)$.

Compliance assistance materials frequently meet the facilities' needs as shown in Table 1a. Lastly, on $24 \%$ of facilities requested assistance from their regulators on ways to reduce discharges.

\subsection{Data Used for Multivariate Statistical Analysis}

This sub-section describes the data actually used for the multivariate statistical analysis based on the limitation of publicly available data on effluent limits and discharge measurements.

\subsubsection{Sample of Survey Respondents with Data on Environmental Performance}

The Permit Compliance System (PCS) database, which records information on facilities permitted within the National Pollutant Discharge Elimination System (NPDES), is the exclusive source of data on effluent limits and discharge measurements. These two data elements permit the construction of this study's measure of environmental performance: discharges relative to effluent limit levels, i.e., relative discharges. The PCS database contains data on environmental performance for major facilities almost exclusively. The survey database contains information for 268 facilities, which includes both "major" and "minor" NPDES facilities. Of these 268 facilities, the PCS database contains data on effluent limits and discharge measurements for 93 facilities, all of which are major NPDES facilities. These 93 facilities represent the sample of analysis. 


\subsubsection{Measures of Environmental Management and Management Index}

To examine the effect of environmental management on environmental performance, this study first describes the additional manipulation of the data on individual measures of management. The survey gathers information on 20 separate measures of environmental management. Table 2 lists all 20 measures. (This table also provides the number of observations with non-missing data, along with the sample means and medians.)

As shown, certain management measures are derived from the underlying survey data. First, the study counts the number of methods used to communicate environmental performance goals to employees. This count measures the extent of environmental management effort. Similarly, the study counts the number of methods used to communicate these goals to external parties. Second, the study focuses initially on treatment upgrades designed to reduce discharges. Third, the study scales three environmental management measures - number of environmental employees, number of wastewater employees, and expenditures on wastewater consultants - by the individual facility's size, as measured by the number of overall employees.

Table 2. Summary Statistics and Classification of Individual Management Measures.

\begin{tabular}{|c|c|c|c|c|c|}
\hline $\begin{array}{l}\text { Management } \\
\text { Measure }\end{array}$ & $\begin{array}{c}\text { Type of Measure: } \\
\text { C = continuous } \\
O=\text { ordinal } \\
D=\text { discrete }(0,1)\end{array}$ & $\begin{array}{c}\text { Timeframe: } \\
\text { A }=\text { Annual } \\
\text { C }=\text { Current } \\
\text { 3 }=3 \text {-Year }\end{array}$ & $\mathbf{N}$ & Median $^{a}$ & Mean $^{\mathrm{a}}$ \\
\hline Stringency of Wastewater Monitoring & $\mathrm{O}$ & $\mathrm{C}$ & 92 & 4 & 3.1957 \\
\hline Audit Team Composition & $\mathrm{O}$ & $\mathrm{C}$ & 88 & 4 & 3.5227 \\
\hline Audit Findings Classification Protocol & $\mathrm{O}$ & $\mathrm{C}$ & 90 & 2.5 & 2.5222 \\
\hline Number of Self-Audits & $\mathrm{C}$ & A & 86 & 1 & 6.3256 \\
\hline $\begin{array}{l}\text { Compliance Assistance Materials } \\
\text { Meeting Facility's Needs }\end{array}$ & 0 & 3 & 86 & 3 & 2.7907 \\
\hline $\begin{array}{l}\text { Role of General Employee: Identifying } \\
\text { and Correcting Non-Compliance }\end{array}$ & $\mathrm{O}$ & $\mathrm{C}$ & 92 & 4 & 3.7609 \\
\hline $\begin{array}{l}\text { Role of General Employee: Identifying } \\
\text { and Preventing Sewer Discharge }\end{array}$ & $\mathrm{O}$ & $\mathrm{C}$ & 89 & 4 & 3.6180 \\
\hline $\begin{array}{l}\text { Communication: Environmental } \\
\text { Performance Goals to Employees }\end{array}$ & $\mathrm{C}$ & $\mathrm{C}$ & 93 & 4 & 3.3226 \\
\hline $\begin{array}{l}\text { Communication: Environmental } \\
\text { Performance Goals to External Party }\end{array}$ & $\mathrm{C}$ & $\mathrm{C}$ & 93 & 2 & 2.3548 \\
\hline Treatment Upgrade: Reduce Discharge & $\mathrm{D}$ & 3 & 88 & 1 & 0.5341 \\
\hline $\begin{array}{l}\text { Assistance from Regulator on } \\
\text { Discharge Reductions }\end{array}$ & $\mathrm{D}$ & 3 & 91 & 0 & 0.2418 \\
\hline ISO 14001 Compliance & $\mathrm{D}$ & $\mathrm{C}$ & 87 & 0 & 0.1264 \\
\hline $\begin{array}{l}\text { Ratio: Facility Environmental } \\
\text { Employees to Facility Employees }\end{array}$ & $\mathrm{C}$ & A & 88 & 0.021 & 0.0561 \\
\hline $\begin{array}{l}\text { College Education of Facility } \\
\text { Environmental Employees (\%) }\end{array}$ & $\mathrm{C}$ & $\mathrm{C}$ & 90 & 0.5 & 0.5500 \\
\hline $\begin{array}{l}\text { Years of Experience for Facility } \\
\text { Environmental Employees }\end{array}$ & $\mathrm{C}$ & $\mathrm{C}$ & 91 & 12 & 13.363 \\
\hline
\end{tabular}


Table 2. Cont.

\begin{tabular}{|c|c|c|c|c|c|}
\hline $\begin{array}{l}\text { Management } \\
\text { Measure }\end{array}$ & $\begin{array}{c}\text { Type of Measure: } \\
\text { C = continuous } \\
O=\text { ordinal } \\
D=\text { discrete }(0,1)\end{array}$ & $\begin{array}{c}\text { Timeframe: } \\
\begin{array}{c}\text { A }=\text { Annual } \\
\text { C }=\text { Current } \\
\text { 3 }=\text { 3-Year }\end{array}\end{array}$ & $\mathbf{N}$ & Median $^{\text {a }}$ & Mean $^{a}$ \\
\hline $\begin{array}{l}\text { Ratio: Wastewater Employees to } \\
\text { Facility Employees }\end{array}$ & $\mathrm{C}$ & $\mathrm{C}$ & 89 & 0.033 & 0.1040 \\
\hline Type of Environmental Training & $\mathrm{O}$ & $\mathrm{C}$ & 93 & 2 & 2.1505 \\
\hline Annual \# of Environ. Training Days & $\mathrm{C}$ & $\mathrm{C}$ & 87 & 5 & 10.204 \\
\hline Attendance at Environ. Training (\%) & $\mathrm{C}$ & $\mathrm{C}$ & 90 & 100 & 89.522 \\
\hline $\begin{array}{l}\text { Ratio: Wastewater Consultant } \\
\text { Expenditures to Facility Employees }\end{array}$ & $\mathrm{C}$ & 3 & 84 & 55.575 & 290.112 \\
\hline
\end{tabular}

The analysis connecting environmental management to environmental performance is not able to accommodate the inclusion of 20 separate measures of environmental management as explanatory factors. Alternatively, the analysis could utilize only a subset of the 20 individual measures. To support this possible approach, one might claim that these 20 measures are not actually capturing 20 distinctively unique aspects of environmental management. However, pairwise correlations of these 20 environmental management measures seem to reject this claim. Surprisingly little correlation exists between the pairs of these measures. Only $12.5 \%$ of the 190 pairwise correlations equal or exceed 0.25 . And only $1.1 \%$ of the pairwise correlations equal or exceed 0.50 . As a matter of fact, $33 \%$ of the 190 pairwise correlations are actually negative though none of these negative correlations prove statistically significant. (A tabulation of the 190 pairwise correlations is available from the author upon request.) This evidence of pairwise correlations seems to indicate that the separate management measures individually provide new information on environmental management. Thus, this study chooses not to limit the set of considered environmental management measures.

Rather than including all of the noted 20 management measures or including only a limited set of these management measures, the analysis combines all 20 measures into an index of environmental management. The study interprets this index as measure of the comprehensiveness of a facility's "system to manage environmental aspects". This approach is consistent with one of the prominent studies to examine the effect of environmental management on environmental performance: Anton et al. [1]. (Khanna and Anton [27] also use this approach but do not examine the effect of environmental management on performance.)

Various protocols are available for creating an index. This study chooses a protocol that seeks to combine various dimensions of management in a comparable fashion, while retaining as much variation as possible. When creating the index, this study divides the set of individual management measures into three categories: (1) continuous measure of management, (2) ordered rank of management, and (3) dichotomous indicator of management. Table 2 categorizes each of the 20 listed measures. As indicated in Table 2, the annual number of self-audits represents an example of a continuous management measure. The stringency of a facility's monitoring program represents an example of an ordered rank measure of management. As shown in Table 1.a, this measure takes one of four values: $1=$ no monitoring, 2 = treatment process monitoring only, $3=$ single point sewer monitoring plus 
treatment process monitoring, and $4=$ single point sewer monitoring plus treatment process monitoring. Unlike continuous measures, the values of ordered rank measures provide only ordinal information. ISO 14001 compliance represents an example of a dichotomous indicator.

Obviously, continuous measures of management provide the most variation across survey respondents. The study wishes to retain this variation, while transforming all management measures into comparable terms so that the analysis may collapse them into a single index. For this purpose, the analysis scales each of the continuous measures by its sample median value; in other words, the analysis divides each measure by its sample median value. This study purposively does not use the sample mean value since it is sensitive to outliers. Consistent with this argument, this study wishes to retain the variation contained in ordered rank measures of behavior. Even though the ordered rank values do not provide cardinal information, this study taps into the ordinal information provided. Similar to the continuous measures, the analysis scales each of the ordered rank measures by its sample median value. Lastly, for comparability with the continuous and ordered rank measures, the analysis scales each of the dichotomous behavioral indicators by its sample mean value. The study purposively does not use the sample median value since it takes either a value of zero, which means the analysis cannot scale the relevant measure since it would involve division by zero, or a value of one, which implies no scaling at all.

After scaling each of the individual management measures, the analysis sums the scaled individual measures, while dividing by the number of measures. However, the analysis must accommodate the presence of missing values for certain measures for particular facilities. Rather than ignoring facilities that do not provide non-missing data for each of the 20 management measures, the analysis accepts slightly less than complete reporting. Specifically, the analysis retains a facility in the sample if the facility provides non-missing data for at least $80 \%$ of the 20 management measures. Of the 93 facilities, this criterion excludes only 2 facilities. Of the 91 remaining facilities, 34 possess less than complete non-missing values for all 20 management measures. Table 3 provides a full tabulation on the number of non-missing management measure values.

Table 3. Number of Non-Missing Management Measures.

\begin{tabular}{cc}
\hline \# of Non-Missing Management Measures & Frequency (\# of facilities) \\
\hline 16 & 2 \\
17 & 2 \\
18 & 13 \\
19 & 17 \\
20 & 57 \\
\hline
\end{tabular}

Since not all of the retained facilities provide complete reporting on the 20 management measures, after summing across the scaled individual measures, the analysis divides by the number of measures with non-missing data. The analysis classifies this ratio as the "raw index". By dividing each sum by the number of non-missing management measures, the raw index represents the average scaled value for the 20 measures. Thus, each measure has the same influence on the index. 
Lastly, the analysis identifies the median value of the raw index and then scales each raw index by this median value, the resulting ratio is classified as the "scaled index". By construction, the scaled index has a median value of 100 . This scaling simplifies the interpretation of the analytical results.

This study chooses not to utilize the protocol of Anton et al. [1], who create an index by capturing each dimension of environmental management with a $(0,1)$ indicator and then summing these indicators. In the author's opinion, this approach unnecessarily disregards variation in most of the individual management measures, thus, losing much distinction within each management measure. Moreover, the choice of the dividing line to establish the presence or absence of a management dimension is potentially problematic since it may be arbitrary. For example, what number of annual self-audits is sufficiently high to warrant the "presence" of environmental management? Lastly, it seems unreasonable to give certain facilities no credit for expending effort to improve their environmental performance simply because the magnitude of their effort falls below some potentially arbitrary threshold.

The scaled index incorporates 20 different measures of management. The survey gathers data on these 20 measures using three different time frames. Table 2 categorizes each of the listed management measures. In the most straightforward time frame, the survey specifically instructs survey respondents to provide annual data over the three-year period of 1999 to 2001. In the second time frame, the survey specifically instructs survey respondents to provide an average level over the three-year period preceding the survey's completion. This three-year window varies across the survey respondents since respondents completed the survey in different months. The first facility responded in March of 2002 and the last facility responded in March of 2003. Thus, the earliest three-year period runs between February, 1999, and January, 2002, and the latest three-year period runs between April, 2000, and March, 2003. In the third time frame, the survey provides no explicit time reference, while implicitly assuming a "current status" reference. Given the nature of the particular management practices being reported, the study reasonably assumes that "current status" applies to the 12-month period preceding the survey's completion. The earliest 12-month period runs between March, 2001, and February, 2002, and the latest 12-month period runs between March, 2002, and February, 2003. In order to combine all 20 behavioral measures into a single index, the study must select a particular year from the first time frame type: annual data for 1999, 2000, and 2001. The obvious choice from this set is 2001 . This selection proves potentially problematic only for the "current status" management as reported by those respondents who completed the survey after January, 2003. This potential problem does not represent a meaningful concern as long as annually reported management in 2001 serves as a reasonable proxy for management conducted in 2002.

\subsubsection{Measure of Environmental Performance}

The study constructs the broadest measure of environmental performance with a focus on the extent of compliance with wastewater discharge limits, i.e., effluent limits. Towards this end, the study generates the ratio between the level of absolute discharges and effluent limit level for each data point stored in the PCS database. Thus, the analysis considers every regulated pollutant, regardless of whether the pollutant is measured as a concentration (e.g., milligrams per liter) or a quantity (e.g., pounds per month). Since both forms of measurement are prominent in the database and effluent limits 
may constrain discharges in one or both measurement forms, the chosen scope is warranted. The analysis is able to compare across all types of pollutant by considering each level of absolute discharge in relationship to the associated effluent limit level, i.e., relative discharges. Given this scope, the sample of survey respondents with data on environmental performance is only limited by the existence of an effluent limit and reported absolute discharges. (In a very small percent of the cases, some facilities actually face a limit of zero for a highly limited set of pollutants; the analysis must omit these cases since the analysis is not able to calculate a ratio between absolute discharges and the effluent limit.) In reality, only the existence of an effluent limit truly limits the sample since the absence of reported absolute discharges applies to only $0.45 \%$ of the monthly data points when an effluent limit exists. Once aggregated to a basis that matches the survey-gathered data, this trivial number of missing data points on absolute discharges essentially disappears. (Given this small percent of cases without data on absolute discharges, which represents only 5 cases, the implementation of a Heckman sample selection procedure to correct for any possible non-reporting bias seems unwarranted and difficult.)

The analysis aggregates the data on relative discharges to a monthly format for each facility. Given this approach, the analysis is concerned about outliers and the sensitivity of the aggregation protocol to the presence of multiple data points for a single pollutant. First, to assess the concern over outliers, the analysis aggregates the data on relative discharges separately based on the (1) relevant mean for a given year and month and particular facility, and (2) the relevant median for a given year and month and particular facility. The study chooses to use the median as the aggregating statistic since it is less sensitive to outliers. Fortunately, the analytical results should not be sensitive to this choice since the two aggregating statistics are very highly correlated. Second, to assess the sensitivity of the aggregation to the presence of multiple data points for a single pollutant, the analysis aggregates the data in two forms. In the first form, the analysis calculates the mean and median values without a distinction given to the pollutant type. In the second form, the analysis first calculates the mean and median values for each pollutant type and then aggregates across the pollutant-specific means and medians. Thus, this second form grants each pollutant only one data point in the final aggregation. For simplicity, the study chooses to use the first aggregation form even though the analysis should not be sensitive to this choice since the two aggregation forms are very highly correlated.

In order to connect environmental management to environmental performance, the analysis must identify the proper time frame for capturing environmental performance. The data on environmental performance are recorded on a monthly basis. In contrast, the scaled management index is recorded only once for each survey respondent. In order to combine all of the individual management measures into the single index, as noted above, the study selects the particular year of 2001 from the set of years including 1999, 2000, and 2001. Consistent with this selection, the study identifies the year of 2001 as the time frame for aggregating environmental performance to match the data on environmental management. The study aggregates the monthly data into an annual format using two aggregating statistics: mean and median. Again, the study chooses to use the median as the aggregating statistic since it is less sensitive to outliers. Fortunately, the analytical results should not be sensitive to this choice since the two aggregating statistics are very highly correlated.

As an alternative aggregation approach, the analysis assumes that the annual management data reported for 2001 serves as a sufficient proxy for the relevant management in 2002 for the survey respondents whose "current status" data on environmental management starts after December, 2001. 
In this alternative aggregation approach, the time frame chosen for aggregating the monthly data on environmental performance corresponds with the "current status" period for each individual respondent. This alternative aggregation approach generates results similar to those reported below.

\subsubsection{Data on Other Factors}

In order to generate additional explanatory factors, this study uses additional information from the EPA Permit Compliance System (PCS) database and additional information from the survey of chemical manufacturing facilities.

\subsubsection{Publicly Available Data}

The PCS database provides information on each facility's (1) four-digit standard industrial classification [SIC] code, (2) effluent limits [as noted above], (3) flow rates, (4) inspections, and (5) enforcement actions. Based on this information, the study constructs explanatory variables for the multivariate statistical analysis. First, the analysis aggregates the four-digit SIC codes into three broader sectoral categories: organic chemicals, inorganic chemicals, and "other" chemicals. (The broad category of organic chemicals includes the following four-digit SIC codes: 2821, 2823, 2824, 2843, $2865,2869,2891$, and 2899. The broad category of inorganic chemicals includes the following four-digit SIC codes: 2812, 2813, 2816, 2819, 2873, and 2874.) Then the study generates one indicator variable for organic chemicals and another indicator for inorganic chemicals; "other" chemicals represent the benchmark category.

Second, the study constructs an overall effluent limit that applies to all of the regulated pollutants contained within the environmental performance measure. The overall effluent limit and environmental performance measure are derived from the very same sample since an observation does not enter into the environmental performance measure unless it contains a positive effluent limit. It would be unproductive to construct an overall effluent limit by summarizing the absolute levels of the pollutant-specific effluent limits since measurement units differ across pollutant types. Instead, the analysis scales each of the reported pollutant-specific absolute effluent limit levels separately by the pollutant-specific mean or median limit found in the sample of all pollutant-specific effluent limits imposed on all chemical manufacturing facilities existing in the PCS database during the period 1998 to 2003. (This wider time frame improves the study's analytical ability to calculate mean and median values that meaningfully represent the regulatory stringency faced by the chemical manufacturing sector.) Specifically, the analysis divides or "scales" each pollutant-specific absolute effluent limit by the pollutant-specific mean or median value to generate a "scaled effluent limit". Each mean and median level is separately calculated for concentration-based discharges and quantity-based discharges. Prior to this scaling, the analysis converts all measurement units into a single comparable unit for each pollutant, again differentiating first by the form of measurement: concentration versus quantity. For example, for concentration-based effluent limits, the analysis converts both milligrams per liter and micrograms per liter to grams per liter before identifying the mean or median value and before scaling by the mean or median value. Next, the analysis averages the concentration-pollutant-specific scaled limit and the quantity-pollutant-specific scaled limit to identify the pollutant-specific scaled limit. 
Finally, the analysis aggregates across all of the pollutants by identifying the mean or median value of the multiple pollutant-specific scaled limits, resulting in the "overall effluent limit".

At the end of this process, data on overall effluent limits are aggregated to a monthly format for each facility, consistent with the underlying monthly environmental performance data. Then the analysis aggregates the overall effluent limits to an annual format for the purposes of multivariate statistical analysis, i.e., estimation. For the estimation of environmental performance, the study uses the annual data on overall effluent limits for the year of 2001. For the estimation of environmental management, the study uses the annual data on overall effluent limits for the year of 2000, i.e., lagged overall effluent limit. The need for a lagged factor is explained below.

In all cases, the study chooses to use the median value, rather than the mean value, when aggregating data on effluent limits since the median is less sensitive to outliers. Fortunately, the analytical results should not be sensitive to these choices since the two aggregating statistics - median and mean - are very highly correlated in all instances.

Third, the study constructs a proxy for flow capacity based on monthly data for flow rates. Specifically, the proxy represents the average flow rate over the preceding 12 -month period. The study must aggregate data on this flow capacity factor within a time period consistent with each of the two dependent variables being estimated in the multivariate statistical analysis: environmental performance and environmental management. For the estimation of environmental performance, the study aggregates the data on flow capacity within the year of 2001; for the estimation of environmental management, the study aggregates the data on flow capacity within the year of 2000 , i.e., lagged flow capacity proxy. Again, the need for a lagged factor is explained below. In both cases, the study aggregates the data on flow capacity using separately the mean value and the median value yet chooses to use the median value since the median is less sensitive to outliers. Fortunately, the analytical results should not be sensitive to these choices since the two aggregating statistics - median and mean - are very highly correlated in both instances: 2001-based flow capacity proxy and 2000-based flow capacity proxy.

Fourth, the study uses data on inspections performed by federal and state regulators and enforcement actions taken by federal entities. Both the PCS database and the EPA Docket database provide data on federal fines, while only the Docket database provides data on federal injunctive relief sanctions and federal Supplemental Environmental Projects (SEPs). Injunctive relief sanctions represent court-imposed orders to perform a particular beneficial act or to stop performing a particular harmful act that relates to a facility's operation. SEPs represent court-imposed orders to perform an environmentally beneficial act that may not be related to a facility's operation (e.g., restore a local wetland). The study integrates the PCS and Docket databases. The identified set of enforcement actions - fines, injunctive relief sanctions, and SEPs - are collectively denoted as "sanctions". When examining the monetary value of sanctions, the analysis deflates all dollar-denominated values for imposed sanctions to 2001 levels using the Consumer Price Index.

The analysis examines the influence of particular government interventions-inspections and sanctions - in two dimensions. The first dimension considers the general threat of facing an intervention, i.e., future regulatory pressure. The second dimension considers facility-specific updates to this general threat of facing an intervention based on the particular facilities' recent experiences with government interventions, i.e., updates to the threat of future regulatory pressure based on recent regulatory pressure. Each facility gauges its expectation of the general threat of monitoring and 
enforcement based on the observed experience of other similar facilities, i.e., each facility uses others' experiences to form its own beliefs [30]. This need to form expectations about interventions stems from the uncertain nature of inspections and sanctions.

When capturing the general threat of sanctions, the analysis examines the count of sanctions imposed on other similar facilities: major chemical facilities in the same relevant location and same time period (specifically, same EPA region and same year of 2001). The analysis adjusts these sanction aggregate values for differences in the number of major chemical facilities across EPA regions by dividing each aggregate count of enforcement actions by the number of other major chemical facilities operating in each EPA region during the given year of 2001. By generating the general threat measures based on the sanctions imposed in 2001, the analysis assumes that facilities form forward-looking expectations to understand the ex ante threat of sanctions $[13,14]$.

General threats also concern inspections. To capture the threat (or likelihood) of an inspection, the analysis employs two proxies based on the annual aggregate count of inspections against other similar facilities: major chemical facilities in the same EPA region and same year of 2001. One proxy captures the state inspection likelihood and the other proxy captures the federal inspection likelihood. To adjust for differences in the number of other facilities across states and EPA regions, the analysis divides each aggregate inspection count by the number of other major chemical facilities operating in each state or EPA region during the given year of 2001.

The general threat of government interventions represents only the first dimension. The other dimension relates to specific updates to the general threat stemming from particular facilities' own recent experiences with government interventions. Thus, these experiences influence both environmental management and performance with a lag. Even though the study measures the exact date of an intervention and discharges are recorded on a monthly basis, the constructed environmental management index reflects data recorded on an annual basis. These differences in recording frequency affect the chosen construction of specific updates to threat measures for use as regressors in the multivariate statistical analysis. Rather than generating two sets of specific update measures - one for management and one for performance, the study chooses to generate a single set. Constrained by the environmental management index, the study constructs specific update measures based on the interventions taken in the preceding calendar year. Without this type of separation, some of the environmental management may actually precede some of the government interventions in a given year. In the case of enforcement, the study generates the cumulative count of sanctions imposed on a specific facility in the preceding calendar year. In the case of inspection-related specific updates, the study generates the cumulative count of inspections conducted by the state at a specific facility in the preceding calendar year and generates the similar cumulative count of inspections conducted by the EPA regional offices.

As the primary measure of enforcement-related interventions, this study uses the count of sanctions. As an alternative measure, this study uses the dollar value of the imposed sanctions. Thus, the analysis separately uses two forms for measuring sanctions: (1) count of sanctions, and (2) dollar value of sanctions. The alternative measure generates results highly similar to those reported for the primary measure of sanction counts. 


\subsubsection{Survey Data}

This study also uses additional information gathered by the aforementioned survey, specifically information on the characteristics of chemical manufacturing facilities and the characteristics of the firms that own the surveyed facilities: year in which the facility was built, number of facility employees, principal wastewater treatment technologies employed at the facility for treating biological oxygen demand (BOD) and total suspended solids (TSS), and firm ownership structure. Table 4 tabulates these data on facility and firm characteristics. As shown, the median year in which a facility was built equals 1981. Based on this information, the study calculates the facility's age. The median number of facility employees ranges between 105 and 110 depending on the year. Interestingly, 42\% of the survey respondents indicate no use of BOD removal technologies and $31 \%$ of the respondents indicate no use of TSS removal technologies; thus, the potential role for a system to manage environmental aspects appears substantial. A majority of the survey respondents are owned by either publicly-held corporations (46\%) or privately-held corporations $(36 \%)$.

While not obviously a facility characteristic, for the purposes of connecting environmental management practices to environmental performance, this study designates the presence of treatment technologies as at least "pre-existing conditions", especially since their installation most likely proceeds the adoption of a system to manage environmental aspects.

Table 4. Facility and Firm Characteristics of Survey Respondents.

Table 4a. Qualitative Characteristics.

\begin{tabular}{llc}
\hline Characteristic & Category & \% of Facilities \\
\hline Biological Oxygen Demand (BOD) & Absence & 42 \\
Treatment Technology & Presence & 58 \\
\hline Total Suspended Solids (TSS) & Absence & 31 \\
Treatment Technology & Presence & 69 \\
\hline & Sole proprietorship & 5 \\
& Partnership & 6 \\
Firm Ownership Structure & Publicly held & 46 \\
& Privately held & 36 \\
& Other & 7 \\
\hline
\end{tabular}

Table 4b. Quantitative Characteristics.

\begin{tabular}{lcc}
\hline Characteristic & \multicolumn{2}{c}{ Summary Statistics } \\
\hline \multirow{2}{*}{ Year in which Facility was Built } & Mean & 1982 \\
& Median & 1981 \\
& Standard Deviation & 9.5 \\
\hline \multirow{2}{*}{ Number of Facility Employees } & Mean & 259 \\
as Full-Time Equivalents (FTE) in 2000 & Median & 110 \\
& Standard Deviation & 485 \\
\hline \multirow{2}{*}{ Number of Facility Employees } & Mean & 251 \\
as Full-Time Equivalents (FTE) in 2001 & Median & 105 \\
& Standard Deviation & 491 \\
\hline
\end{tabular}


Lastly, the study uses survey-based information on the facilities' perceptions of local community pressure, perceptions of the own facility's local economic importance, and depiction of the overall enforcement approach taken by a particular facility's water regulator. Local community pressure is recorded on a 10-point scale, where " 1 " reflects extremely low pressure and "10" reflects extremely high pressure. Local economic importance is perceived as either "very little", "small", "significant", or "great". The analysis generates an indicator of substantial economic impact that takes a value of one if the facility's economic impact is "significant" or "great", with the benchmark category including "very little" or "small" impact. The overall enforcement approach represents the relationship between the regulated entity and its wastewater-related regulator; see Glicksman and Earnhart [31]. This relationship or is depicted as either "cooperative" or "coercive". The analysis generates an indicator variable to capture the "cooperative" approach, with the "coercive" approach as the benchmark category. This variable provides a richer understanding of how government interventions are applied: whether (1) the regulator monitors for non-compliance and imposes sanctions whenever monitoring detects non-compliance or (2) the regulator uses inspections to provide assistance and imposes sanctions only as a last resort.

\section{Statistical Analysis: Framework, Methods, Results, and Discussion}

\subsection{Analytical Framework}

Using the survey-gathered data on environmental management, along with facility and firm characteristics, and publicly available data on environmental performance, effluent limits, flow rates, and government interventions, this study explores the influence of environmental management on environmental performance, as captured by the ratio of wastewater discharges to permitted effluent limits. This discharge ratio reflects the extent of compliance with imposed effluent limits.

To examine the effect of the created environmental management index on environmental performance, this study constructs a recursive simultaneous equations framework for explaining environmental management and environmental performance. This framework is recursive in that current management affects current environmental performance, yet current performance does not affect current management. Formally, let $Y_{1}$ represent environmental management and let $Y_{2}$ represent environmental performance. Moreover, let $X_{l}$ represent the exogenous factors affecting only environmental management and let $X_{2}$ represent the exogenous factors affecting only environmental performance. Also, let $W$ represent the exogenous factors affecting both management and performance. Given this notation, the recursive simultaneous equations system takes the following structure:

$$
\begin{aligned}
& \mathrm{Y}_{1}=\mathrm{f}\left(\mathrm{X}_{1}, \mathrm{~W}\right)+,{ }_{1}, \text { and } \\
& \mathrm{Y}_{2}=\mathrm{f}\left(\mathrm{X}_{2}, \mathrm{~W}, \mathrm{Y}_{1}\right)+, 2
\end{aligned}
$$

where,$_{1}$ and, 2 represent the additive error terms associated with management and performance, respectively, and $\mathrm{f}(\cong)$ and $\mathrm{g}(\cong)$ represent the functions underlying environmental management and environmental performance, respectively. When estimating environmental performance, the analysis considers two specifications: linear and semilog. In order to implement the semilog specification, the statistical analysis must address the fact that the level of relative discharges equals zero for some 
facilities. In other words, some facilities controlled their discharges so much that these facilities eliminated their discharges. This concern applies to only 7 of the 93 facilities in the sample. Since the $\log$ function is not defined for zero values, the analysis replaces the zero value with an appropriate proxy value: the midpoint between zero and the lowest positive environmental performance level reported in the sample. This approach is legitimate if every facility pollutes at least a little bit every month. From this perspective, the reported value of zero is merely an approximation of some small positive discharge level.

For consistency with the two specifications used to estimate environmental performance, the statistical analysis considers only a linear specification when estimating environmental behavior. The statistical analysis does not consider estimating environmental management using a semilog specification and estimating environmental performance using a log-linear specification because some of the regressors cannot be log-transformed since they accurately take zero values (e.g., government intervention-based measures) and a mixed set of non-transformed and log-transformed regressors is difficult to justify.

Given the structure shown in Equations (1) and (2), the statistical analysis is able to estimate the two equations separately and use the actual value of $Y_{1}$ as a regressor in Equation (2) without any accommodation as long as the two error terms, , 1 and ,2, are not correlated [32]. Put differently, the analysis is able to estimate the two equations separately as long as environmental management represents an exogenous regressor in the Equation (2), i.e., environmental management is exogenous with respect to environmental performance.

To assess this exogeneity, the study utilizes a Hausman Test of Exogeneity, as described by Wooldridge [33] and applied by Anton et al. [1]. If the test results indicate that the null hypothesis of exogeneity is rejected, then the analysis must accommodate the endogeneity of environmental management. As another way of expressing this endogeneity, the unobserved variables, as reflected in the error terms of the management and performance equations $\left(,_{1}\right.$ and ,2), are correlated. This correlation stems from the likelihood that an unobserved variable (or variables) influences both the level of the environmental management index and the level of environmental performance.

If the null hypothesis of exogeneity is rejected, the instrumental variables approach of two-stage least squares estimation represents the primary means for treating this endogeneity. The two-stage least squares approach estimates the two-equation simultaneous equation system jointly. Moreover, this approach uses a set of instruments, which represent variables that are correlated with the environmental management index yet are uncorrelated with the error term associated with environmental performance, ,2 [1]. (Details on the chosen set of instruments are described below.)

When implementing the Hausman Test of Exogeneity, the statistical analysis follows the procedure described in Wooldridge [33]. Accordingly, the analysis estimates environmental management as a function of all the exogenous factors contained in the simultaneous equations system, retains the residuals, and includes the retained residuals as an additional explanatory variable in the estimation of environmental performance. Using a standard t-test, the statistical analysis assesses the statistical significance of the coefficient associated with the residuals variable. The t-test statistic and p-value associated with this test are reported in subsequent tables.

The implementation of the Hausman Test of Exogeneity generates results that demonstrate that one cannot reject the null hypothesis of exogeneity for environmental management with respect to 
environmental performance. This conclusion is highly robust to the specification used to estimate environmental performance and the regressor set used to explain environmental performance (and environmental management). Thus, the study reports and interprets the results of the equation-by-equation analysis of the recursive two-equation simultaneous equations system without any further accommodation.

Even though the study does not need to implement a two-stage least squares estimation procedure, for the purposes of robustness, the study invokes this procedure. In this implementation, the analysis uses the two regressors vectors of $\mathrm{X}_{1}$ and $\mathrm{W}$ as the full set of instruments, as described by Wooldridge [33]. While the effect of environmental management on environmental performance proves insignificant in this two-stage least squares estimation, the sign of this effect is the same as and the magnitude of this effect is highly comparable to the effect reported below. (Estimation results from the two-stage least squares procedure are available from the author upon request.)

As a related matter, government interventions may also be endogenous relative to environmental performance. However, separation in time arguably implies that lagged government interventions are exogenous relative to current environmental performance.

\subsection{Estimation of Environmental Management: Instrumental Variables}

This study begins the estimation of the recursive two-equation simultaneous equations system by estimating environmental management. In order to implement the Hausman Test of Exogeneity and the two-stage least squares estimation, the analysis must identify explanatory factors that affect management but not performance. Without these particular factors, one is unable to utilize the instrumental variables aspect of the Hausman Test and the two-stage least squares estimation routine. Consistent with the approach taken by Anton et al. [1], the analysis considers strongly the timing of the explanatory factors' effects in order to identify useful instrumental variables. The distinction relies heavily upon the understanding that current conditions affect current environmental performance, while current conditions need not affect current environmental management. Instead, past conditions most likely affect current environmental management [1]. Thus, while environmental performance depends on current conditions (which must be true), management depends on lagged conditions, assuming that facilities' decision-makers need time to implement their decisions and that they draw upon the conditions in place when they are making their decisions rather than anticipating the conditions that may be in place at the time of implementation. Based on this logic, the study identifies the lagged values of certain factors as the instrumental variables needed for estimation. Specifically, the study uses lagged values for a facility's flow capacity proxy, overall effluent limit, facility age, and number of facility-level employees. (For other possible factors, the study either lacks data on lagged values or the factors do not vary over the sample period; Anton et al. [1] face similar issues.).

The study selects the year of 2001 as the time frame for connecting the management index to performance. The lagged values used to explain environmental management are drawn from the year of 2000. This choice fits nicely with annually reported and "current status" management measures. This choice may appear problematic for the management measures reported for the three-year period preceding the survey's completion since the earliest three-year period runs between March, 1999, and February, 2002, and the latest three-year period runs between March, 2000, and February, 2003. 
However, the use of the noted lagged values as instrumental variables is fully appropriate since the lagged values from 2000 should help to explain the management decisions made over the broad three-year period and most certainly do not affect environmental performance in 2001.

The study also attempts to identify instrumental variables by comparing the determinants explaining environmental management and environmental performance, consistent with Anton et al. [1]. This procedure identifies an instrumental variable when a particular variable significantly affects environmental management but not environmental performance. Table 5 reports the results stemming from the estimation of environmental management. As shown, the overall enforcement approach (cooperative vs coercive) significantly influences environmental management. Estimation results reveal that this same factor does not significantly affect environmental performance. (Table 5 displays an adjusted R-squared statistic of 0.0828 ; "low" values such as this one is not uncommon in cross-sectional data analysis.)

Table 5. Estimation of Environmental Management Index.

\begin{tabular}{|c|c|c|}
\hline Variable & Coefficient & $p$-value \\
\hline Intercept & 173.107 & 0.0104 \\
\hline Sanction Count: Specific Update & -8.515 & 0.9074 \\
\hline Sanction Count: General Threat & 1092.598 & 0.5689 \\
\hline State Inspections: Specific Update & -11.340 & 0.0468 \\
\hline Federal Inspections: Specific Update & -28.770 & 0.1911 \\
\hline State Inspections: General Threat & 25.309 & 0.0235 \\
\hline Federal Inspections: General Threat & -309.348 & 0.0578 \\
\hline Overall Effluent Limit (lagged) & -0.414 & 0.2628 \\
\hline Cooperative Enforcement Approach ${ }^{a}$ & 105.959 & 0.0942 \\
\hline Local Community Pressure & -45.683 & 0.2828 \\
\hline Substantial Facility Local Economic Impact ${ }^{\text {b }}$ & 5.676 & 0.8422 \\
\hline Flow Capacity (lagged) & 1.431 & 0.6234 \\
\hline Facility Age (lagged) & -0.043 & 0.917 \\
\hline Number of Facility Employees (lagged) & -0.080 & 0.0055 \\
\hline BOD/TSS Treatment Technology & -95.666 & 0.0088 \\
\hline Inorganic Chemical Sector $^{c}$ & -42.996 & 0.1184 \\
\hline Organic Chemical Sector ${ }^{c}$ & -10.091 & 0.6495 \\
\hline Publicly Held Ownership Structure (lagged) ${ }^{d}$ & 18.060 & 0.3368 \\
\hline Number of Observations & \multicolumn{2}{|c|}{82} \\
\hline Adjusted $\mathrm{R}^{2}$ & \multicolumn{2}{|c|}{0.0828} \\
\hline
\end{tabular}

a Omitted category is coercive enforcement approach; ${ }^{b}$ Omitted category is "very little" or "small" economic impact; ${ }^{c}$ Omitted category is "other chemicals" sector; ${ }^{\mathrm{d}}$ Omitted category is all ownership structures except publicly held corporation.

To complete the Hausman Test of Exogeneity, the analysis estimates environmental performance with the residuals-derived measure as a regressor. The Hausman test results are reported at the bottom of Tables 6 and 7. 
Table 6. Estimation of Environmental Performance: Linear Specification.

\begin{tabular}{|c|c|c|c|c|}
\hline \multirow{2}{*}{ Variable } & \multicolumn{2}{|c|}{ Long Regressor Set } & \multicolumn{2}{|c|}{ Short Regressor Set } \\
\hline & Coefficient & $p$-value & Coefficient & $p$-value \\
\hline Intercept & 0.5309 & 0.0001 & 0.4780 & 0.0001 \\
\hline Environmental Management Index & $-497.7 \times 10^{-6}$ & 0.0204 & $-536.1 \times 10^{-6}$ & 0.0087 \\
\hline Sanction Count: Specific Update & 0.0210 & 0.8845 & 0.0732 & 0.6152 \\
\hline Sanction Count: General Threat & -6.6926 & 0.1217 & -3.9819 & 0.3196 \\
\hline State Inspections: Specific Update & -0.0116 & 0.2135 & -0.0057 & 0.4697 \\
\hline Federal Inspections: Specific Update & -0.0168 & 0.7234 & -0.0114 & 0.7661 \\
\hline State Inspections: General Threat & 0.0252 & 0.1769 & 0.0098 & 0.5763 \\
\hline Federal Inspections: General Threat & 0.3370 & 0.2910 & 0.2365 & 0.4301 \\
\hline Overall Effluent Limit & 0.0004 & 0.5183 & $\mathrm{~N} / \mathrm{A}$ & $\mathrm{N} / \mathrm{A}$ \\
\hline Local Community Pressure & -0.1219 & 0.0819 & -0.1081 & 0.0584 \\
\hline Substantial Facility Local Economic Impact ${ }^{\mathrm{a}}$ & -0.0016 & 0.9734 & $\mathrm{~N} / \mathrm{A}$ & $\mathrm{N} / \mathrm{A}$ \\
\hline Flow Capacity & 0.0007 & 0.9111 & $\mathrm{~N} / \mathrm{A}$ & $\mathrm{N} / \mathrm{A}$ \\
\hline Facility Age & -0.0024 & 0.0025 & -0.0017 & 0.0179 \\
\hline Number of Facility Employees & $4.19 \times 10^{-6}$ & 0.9533 & $\mathrm{~N} / \mathrm{A}$ & $\mathrm{N} / \mathrm{A}$ \\
\hline BOD/TSS Treatment Technology & -0.1429 & 0.0138 & -0.1341 & 0.0127 \\
\hline Inorganic Chemical Sector ${ }^{\mathrm{b}}$ & 0.0721 & 0.1637 & $\mathrm{~N} / \mathrm{A}$ & $\mathrm{N} / \mathrm{A}$ \\
\hline Organic Chemical Sector ${ }^{\mathrm{b}}$ & 0.0993 & 0.0274 & $\mathrm{~N} / \mathrm{A}$ & $\mathrm{N} / \mathrm{A}$ \\
\hline Publicly Held Ownership Structure ${ }^{c}$ & 0.0350 & 0.3266 & $\mathrm{~N} / \mathrm{A}$ & $\mathrm{N} / \mathrm{A}$ \\
\hline Number of Observations & \multicolumn{2}{|l|}{75} & \multicolumn{2}{|c|}{85} \\
\hline Adjusted $\mathrm{R}^{2}$ & \multicolumn{2}{|c|}{0.2045} & \multicolumn{2}{|c|}{0.1174} \\
\hline Hausman Test of Exogeneity ( $p$-value) & \multicolumn{2}{|c|}{$1.01(0.3170)$} & \multicolumn{2}{|c|}{$1.04(0.3028)$} \\
\hline \multicolumn{5}{|c|}{$\begin{array}{l}\text { a Omitted category is "very little" or "small" economic impact; }{ }^{\mathrm{b}} \text { Omitted category is "other chemicals" } \\
\text { sector; }{ }^{\mathrm{c}} \text { Omitted category is all ownership structures except publicly held corporation. }\end{array}$} \\
\hline \multirow{2}{*}{ Variable } & \multicolumn{2}{|c|}{ Long Regressor Set } & \multicolumn{2}{|c|}{ Short Regressor Set } \\
\hline & Coefficient & $p$-value & Coefficient & $p$-value \\
\hline Intercept & 2.6399 & 0.2498 & -0.9983 & 0.2584 \\
\hline Environmental Management Index & -0.0112 & 0.0057 & -0.0105 & 0.0047 \\
\hline Sanction Count: Specific Update & 1.1620 & 0.6466 & 1.2329 & 0.6351 \\
\hline Sanction Count: General Threat & -90.3629 & 0.2616 & -46.9973 & 0.5179 \\
\hline State Inspections: Specific Update & -0.0366 & 0.8332 & 0.0845 & 0.5567 \\
\hline Federal Inspections: Specific Update & 0.4855 & 0.5852 & 0.7148 & 0.3059 \\
\hline State Inspections: General Threat & 0.2904 & 0.4030 & 0.0057 & 0.9857 \\
\hline Federal Inspections: General Threat & 5.5177 & 0.3550 & 4.6507 & 0.392 \\
\hline Overall Effluent Limit & $129.6 \times 10^{-6}$ & 0.9918 & $\mathrm{~N} / \mathrm{A}$ & $\mathrm{N} / \mathrm{A}$ \\
\hline Local Community Pressure & -0.7216 & 0.5772 & $\mathrm{~N} / \mathrm{A}$ & N/A \\
\hline Substantial Facility Local Economic Impact ${ }^{a}$ & 0.6086 & 0.5068 & $\mathrm{~N} / \mathrm{A}$ & $\mathrm{N} / \mathrm{A}$ \\
\hline Flow Capacity & -0.0138 & 0.9105 & $\mathrm{~N} / \mathrm{A}$ & N/A \\
\hline Facility Age & -0.0521 & 0.0006 & -0.0341 & 0.0082 \\
\hline Number of Facility Employees & $496.7 \times 10^{-6}$ & 0.7108 & N/A & N/A \\
\hline BOD/TSS Treatment Technology & -1.5487 & 0.1465 & $\mathrm{~N} / \mathrm{A}$ & $\mathrm{N} / \mathrm{A}$ \\
\hline
\end{tabular}


Table 7. Cont.

\begin{tabular}{|c|c|c|c|c|}
\hline \multirow{2}{*}{ Variable } & \multicolumn{2}{|c|}{ Long Regressor Set } & \multicolumn{2}{|c|}{ Short Regressor Set } \\
\hline & Coefficient & $p$-value & Coefficient & $p$-value \\
\hline Inorganic Chemical Sector $^{b}$ & 0.7817 & 0.4170 & $\mathrm{~N} / \mathrm{A}$ & $\mathrm{N} / \mathrm{A}$ \\
\hline Organic Chemical Sector $^{b}$ & 0.8511 & 0.3036 & $\mathrm{~N} / \mathrm{A}$ & $\mathrm{N} / \mathrm{A}$ \\
\hline Publicly Held Ownership Structure ${ }^{c}$ & 0.8354 & 0.2125 & $\mathrm{~N} / \mathrm{A}$ & $\mathrm{N} / \mathrm{A}$ \\
\hline Number of Observations & \multicolumn{2}{|c|}{75} & \multicolumn{2}{|c|}{85} \\
\hline Adjusted $\mathrm{R}^{2}$ & \multicolumn{2}{|c|}{0.1281} & \multicolumn{2}{|c|}{0.0896} \\
\hline Hausman Test of Exogeneity ( $p$-value) & \multicolumn{2}{|c|}{$0.46(0.6660)$} & \multicolumn{2}{|c|}{$0.47(0.6366)$} \\
\hline
\end{tabular}

\subsection{Estimation of Environmental Performance}

\subsubsection{Set of Explanatory Factors}

This sub-section describes the estimation of environmental performance as a function of several explanatory factors. The environmental management index represents the primary explanatory factor. The regressor set also includes government intervention-related measures, which reflect one component of regulatory pressure, representing one form of external pressure. As another component of regulatory pressure, the regressor set includes the overall effluent limit; tighter effluent limits most likely undermine facilities' abilities to comply, driving up relative discharges. As a second form of external pressure, the regressor set includes a measure of perceived local community pressure. Related to local community pressure, the regressor set includes a measure of the perceived local economic importance of the individual facility. This measure helps to control for any tempering of community pressure based on a facility's importance in a community. Presumably, a local community is less likely to pressure a facility for better performance if that facility plays a greater economic role in the community; i.e., fewer residents are willing to ruffle the feathers of the goose who lays the golden egg. The indicator of substantial economic impact takes a value of one if the facility's economic impact is "significant" or "great" (versus "very little" or "small"). [Use of an alternative formulation that utilizes only "great" economic impact to indicate the presence of substantial economic impact generates results comparable to those reported below.]

In addition, the regressor set includes various facility characteristics: (1) presence of a BOD treatment technology and/or TSS treatment technology, (2) sectoral indicators, (3) age of the facility, (4) number of facility-level employees, and (5) flow capacity proxy. Treatment technologies capture the effect of BOD- or TSS-related pollution control equipment on discharges. This technology variable takes a value of zero if neither technology is present, a value of 0.5 if only one treatment technology is present, and a value of one if both technologies are present. Industrial sub-sector indicators help to control for variation in facilities' abilities to monitor their operations, including their production processes, based on the type of product being manufactured. The analysis includes two sectoral indicators: organic chemical indicator and inorganic chemical indicator, with "other chemicals" as the omitted category. Facility age potentially proxies for the vintage of the technology embodied within the facility's production equipment. Frequently, use of newer production equipment generates less 
waste. As long as older facilities operate older production equipment, older facilities might be expected to generate worse environmental performance, i.e., higher relative discharges. Environmental performance may depend on the size of the regulated facility; the number of employees represents a common proxy of facility size. By assessing the influence of this facility size proxy, the analysis may be able to discern the presence of any economies or diseconomies of scale with respect to facility-level production. Flow capacity represent an alternative angle for capturing economies or diseconomies of scale: where the number of facility employees measures the scale of production, flow capacity measures the scale of pollution control.

Lastly, the regressor set includes one firm characteristic: firm ownership structure, as represented by the distinction between publicly held firms and all other ownership forms (especially privately held corporations). Ownership structure captures a host of dimensions; for example, facilities owned by publicly held firms may possess greater access to external financing for environmentally-related investment. The statistical analysis includes a "publicly-held" indicator, with "all other ownership forms" as the omitted category.

\subsubsection{Interpretation of Results}

When estimating environmental performance as a function of the described explanatory factors, the analysis considers two specifications: linear and semilog. Tables 6 and 7 report the estimation results of the linear and semilog specifications, respectively. Regardless of the specification, the results strongly indicate that better environmental behavior leads to better environmental performance, i.e., lower relative discharges, greater compliance with effluent limits. Thus, the conclusion is robust to the specification type. (Tables 6 and 7 display adjusted R-squared statistics ranging between 0.0896 and 0.2045; such "low" values are not uncommon in cross-sectional data analysis.)

The conclusion is also robust to the regressor set. As a robustness check, the statistical analysis also estimates environmental performance using a slightly trimmed regressor set that excludes some of the regressors found insignificant based on the estimation using the full set of regressors, while retaining insignificant explanatory factors of special interest, e.g., government intervention-related factors. The analysis also estimates environmental performance using a fully streamlined regressor set that consists of only the statistically significant factors and factors capturing government interventions. Tables 6 and 7 report the estimation results using the full set of regressors and the fully streamlined set. (As the estimation limits the number of regressors, the sample size grows because fewer factors with missing data are restricting the sample size, i.e., the study does not constrain the sample size as it alters the regressor set.) Regardless of the regressor set, greater environmental management leads to better compliance with effluent limits, i.e., stronger environmental performance.

The reported conclusion is also robust to alternative constructions of the environmental management index. In particular, the conclusion is robust to the following modifications: (1) exclusion of the role of general employees in the identification and prevention of discharges into a sewer system [which need not apply to the analysis of discharges to surface water], (2) the replacement of the presence of "a treatment upgrade designed to limit wastewater discharges" with the presence of "any treatment upgrade" [which may capture environmental management more broadly], (3) the replacement of per employee expenditures on external wastewater consultants with absolute 
expenditures on external wastewater consultants [which may more accurately capture the impact of these expenditures], and (4) the exclusion of all management practices measured over the three-year period preceding the survey's completion [which may not fit cleanly with the chosen construction of government interventions and lagged facility characteristics].

In sum, the conclusion regarding the effect of environmental management on environmental performance is robust to the choice of specification, regressor set, and management index construction. Moreover, the actual magnitude of the effect is robust across the regressor sets within each specification.

Interpretation of the coefficients associated with other explanatory factors generate additional conclusions. These interpretations concern the direct effects of factors on environmental performance. While the study seeks to assess these direct effects, it must acknowledge that direct effects may be difficult to identify. To illustrate this claim, imagine that environmental management represents the only non-random element driving environmental performance after controlling for the end-of-pipe treatment technology employed by a facility (as done in the multivariate statistical analysis). This conjecture seems reasonable if the measure of environmental management comprehensively captures all of a facility's efforts to control discharges not related to end-of-pipe treatment. If one is able to measure all environmental management effort and it represents the only non-random element driving performance beyond end-of-pipe treatment, then no other non-random element directly affects performance ("direct effect"). Only if one is not able to measure all dimensions of management will this situation generate direct effects beyond end-of-pipe treatment. In this case, a factor will appear to affect both management and performance because the factor that influences a facility to modify its management in ways that are measured may also prompt a facility to modify its management in ways that are not measured. For example, assume that the type of production, as proxied by the facility's industrial sector classification, influences both measured management and un-measured management. In this case, production type affects both management (as measured) and performance (indirectly via production type's influence on un-measured management).

Taken as a whole, the estimation results provide evidence for the argument that direct effects on environmental performance are difficult to identify once the estimation sufficiently controls for the influence of environmental management (along with end-of-pipe treatment). The linear specification results indicate that only four other factors prove significant. The semilog specification results indicate that only a single other factor proves significant. Given the described perspective, the significant direct effects may stem from the presence of un-measured management influences stemming from local community pressure, facility age, and production type (as captured by the organic chemical sector indicator). The significant influence of BOD/TSS treatment technology is also consistent with the described argument since the treatment technology factor controls for pollution abatement efforts not related to environmental management practices.

As for the particular direct effects, the estimation results support the following conclusions. Greater local community pressure improves environmental performance, as indicated by a negative coefficient, implying a lower level of relative discharges when pressure is stronger. Older facilities generate better environmental performance. This result is inconsistent with better technologies being embodied within newer facilities. Perhaps, older facilities have more time to understand and control their discharges. Facilities operating within the organic chemical sub-sectors generate worse environmental performance than facilities operating in "other" sub-sectors, as indicated by a positive coefficient, 
implying a higher level of relative discharges for organic chemical facilities relative to "other" chemical facilities. Lastly, as expected, a stronger presence of BOD/TSS treatment technologies improves environmental performance.

\subsection{Estimation of Environmental Management: Interpretation of Results}

This last sub-section returns to the results generated by estimating the environmental management index in order to interpret these results. This interpretation helps to identify the indirect effects of factors on environmental performance via their influence on environmental management. Table 5 reports the estimation results. First, the general threat of state inspections improves environmental management, as indicated by a positive coefficient, implying that an increase in the threat of state inspections leads to stronger environmental management. In contrast, specific updates to the general threat, as captured by lagged state inspections, undermine environmental management, as indicated by a negative coefficient, implying that an increase in the number of state inspections completed at a given facility in the preceding calendar year leads to weaker environmental management. It is difficult to reconcile these two related results. Second, the general threat of federal inspections undermine environmental management, while lagged federal inspections do not influence environmental management. Third, a cooperative enforcement approach leads to stronger environmental management than does a coercive enforcement approach. These results are reasonably consistent. Relative to federal inspections, state inspections are more likely to provide assistance to regulated facilities. Rather than providing assistance, federal inspections are frequently used to cajole recalcitrant facilities. The expectation of assistance from state inspectors appears to prompt facilities to conduct stronger environmental management, while the expectation of federal "arm twisting" appears to reduce facilities' desires to conduct environmental management. In other words, a cooperative approach promotes more environmental management than a coercive approach.

As shown in Table 5, facility characteristics also affect environmental management. Older facilities expend weaker environmental management effort. Older facilities may be less likely to conduct environmental management, especially self-audits, because facilities built years ago were not designed to facilitate easy self-monitoring. This explanation indicates that the costs of environmental management are just as relevant as the benefits of environmental management. Similarly, larger facilities - as measured by the number of facility employees - conduct less environmental management. This result may reveal that diseconomies of scale exist with respect to production levels. In contrast, flow capacity does not significantly affect environmental management; this result appears to indicate that neither economies nor diseconomies of scale exist with respect to pollution control. Lastly, a stronger presence of BOD/TSS treatment technologies weakens environmental management. As long as treatment technologies are sufficiently pre-determined in the two-equation simultaneous equations system, this result appears to indicate that pollution control equipment and environmental management are substitutes.

\section{Conclusions}

In summary, this empirical analysis of U.S. major chemical manufacturing facilities permitted to discharge wastewater pollutants reveals that better environmental management, as measured across an array of dimensions, leads to more successful environmental performance, as measured by relative 
discharges, i.e., actual discharges relative to discharge limits, which reflects the extent of compliance with imposed discharge limits. This conclusion is fully robust to the choice of specification (i.e., function connecting the explanatory factors to the level of environmental performance), choice of regressor set (i.e., collection of explanatory factors), and chosen construction of the index used to capture the array of environmental management dimensions within a single measure. Thus, based on the studied sample of regulated facilities, better environmental management improves compliance with environmental regulations. Since the measure of compliance also captures the extent of over-compliance, the results reveal that better environmental management may reflect efforts that achieve "beyond compliance" success.

By using wastewater discharges as the sole measure of environmental performance, this study might miss the possible switching of industrial pollution into other media, such as air and land. Based on previous research, the potential for this type of switching does not seem substantial [34].

Lastly, this study's empirical results possess policy implications. Since better environmental management leads to better wastewater-related environmental performance, state and federal environmental protection agencies may wish to implement government programs that seek to induce and encourage better environmental management. For example, environmental protection agencies may wish to offer technical assistance on particular forms of environmental management through workshops, technical bulletins, demonstration projects, or one-on-one coaching. As another example, environmental protection agencies may offer positive publicity through participation in voluntary programs that focus on implementation of certain forms of environmental management. As a final example, environmental protection agencies may grant greater latitude regarding compliance with effluent limits over the short-term as regulated facilities introduce new or better environmental management practices.

\section{Appendix: Incomplete Response to Survey of Chemical Manufacturing Facilities}

This appendix assesses the incomplete response to our original survey of chemical manufacturing facilities. Given the survey's non-response rate of $73 \%$, the potential for sample selection bias is a valid concern. As the initial assessment of this concern, we compare the original sample of 1,003 potentially eligible facilities to the 268 facilities that actually completed the survey. Based on this comparison, we find no systematic state or regional bias in survey participation. For example, only the Midwest region is slightly over-represented in the response group, and only the Northeast region is slightly under-represented. These differences, however, are small. In addition, across most of the states, the difference between representation in the original sample and representation in the response group averages less than two percent. In contrast, our initial assessment reveals some difference in the participation of major facilities versus minor facilities. In the original sample, 69 percent of facilities are minor facilities and 31 percent are major facilities. In the group of survey respondents, major facilities are slightly over-represented at 39 percent. This difference proves statistically significant.

As a stronger assessment, we test for sample selection bias using the Heckman two-stage sample selection procedure [29]. As part of the first stage of this procedure, we assess whether any relevant factors appear to affect a facility's decision to complete our survey once it is contacted. This assessment reveals a bias in a single dimension: major facilities were more likely to respond to the survey than were minor facilities. Put differently, the Heckman analysis indicates that only the 
distinction between minor and major facilities proves important for explaining whether or not a contacted facility completed the administered survey. The Heckman analysis demonstrates that neither the preceding history of inspections nor the preceding enforcement actions against a particular facility explains whether or not a contacted facility responded to the survey. Moreover, the analysis demonstrates that the decision to respond is not explained by the EPA region in which a particular facility resides. Thus, even if the threat of inspections and enforcement actions varies across EPA regions, this variation does not explain whether or not a contacted facility responds to the survey. (The analysis is not able to control for variation across states in a similar fashion given the large number of individual states, relative to the sample size.)

As the third form of assessment, we incorporate information on discharges and effluent limits for which data are publicly available only for major facilities. Given this data constraint, the third form of assessment focuses exclusively on major facilities. Using Two-Sample Means T-tests, the study demonstrates that the sample of survey respondents and survey non-respondent facilities generated extremely similar discharge-to-limit ratios (i.e., actual discharges divided by permitted limits) for the time period covered by the survey instrument: January, 1999, to March, 2003. This analysis considers separately the two most prominent wastewater pollutants: Total Suspended Solids (TSS) and Biological Oxygen Demand (BOD). For the TSS discharge-to-limit ratio, the two sample means both equal 0.267 and the t-test p-value is 0.969 . For the BOD discharge-to-limit ratio, the two sample means are nearly identical -0.261 and 0.256 - and the t-test $p$-value is 0.616 .

Based on other observable measures, including EPA region, preceding history of inspections, preceding history of enforcement actions, and industrial sector, major survey respondents and major survey non-respondents do not differ. Thus, in all observable regards, the studied major facilities are representative of the relevant population.

For all these reasons, the study does not correct for any potential sample selection bias. This lack of correction is consistent with recent prominently published studies of environmental management practices $[1,3]$.

\section{Acknowledgments}

I thank Dylan Rassier for his research assistance. This manuscript was developed under a STAR Research Assistance Agreement No. R-82882801-0 awarded by the U.S. Environmental Protection Agency. It has not been formally reviewed by the EPA. The views expressed in this document are solely those of Dietrich Earnhart. The EPA does not endorse any products or commercial services mentioned in this manuscript.

\section{Conflict of Interest}

The authors declare no conflict of interest.

\section{References}

1. Anton, W.R.Q.; Deltas, G.; Khanna, M. Incentives for environmental self-regulation and implications for environmental performance. J. Environ. Econ. Manag. 2004, 43, 632-654. 
2. Crow, M. Beyond experiments. Environ. Forum 2000, 37, 18-29.

3. Arimura, T.; Hibiki, A.; Katayama, H. Is a voluntary approach an effective environmental policy instrument? A case for environmental management systems. J. Environ. Econ. Manag. 2008, 55, 281-295.

4. Daddi, T.; Magistrelli, M.; Frey, M.; Iraldo, F. Do Environmental management systems improve environmental performance? Empirical evidence from italian companies. Environ. Dev. Sustain. 2011, 13, 845-862.

5. Dasgupta, S.; Hettige, H.; Wheeler, D. What improves environmental compliance? Evidence from mexican industry. J. Environ. Econ. Manag. 2000, 39, 39-66.

6. Barla, P. ISO 14001 Certification and environmental performance in Quebec'S pulp and paper industry. J. Environ. Econ. Manag. 2007, 53, 291-306.

7. Dahlström, K.; Howes, C.; Leinster, P.; Skea, J. Environmental management systems and company performance: Assessing the case for extending risk-based regulation. Eur. Environ. 2003, 13, 187-203.

8. Hertin, J.; Berkhout, F.; Wagner, M.; Tyteca, D. Are "Soft" Policy Instruments Effective? The Link between Environmental Management Systems and the Environmental Performance of Companies; SPRU Electronic Working Paper Series; University of Sussex: Brighton, UK, 2004.

9. Hertin, J.; Berkhout, F.; Wagner, M.; Tyteca, D. Are EMS environmentally effective? The link between environmental management systems and environmental performance in European companies. J. Environ. Plan. Manag. 2008, 51, 259-283.

10. Andrews, R.N.L.; Amaral, D.; Darnall, N.; Gallagher, D.R.; Edwards, D., Jr.; Hutson, A.; D’Amore, C.; Sun, L.; Zhang, Y. Environmental Management Systems: Do They Improve Performance? Available online: http://www.c2e2.org/documents/completeexecutive summary.pdf (accessed on 4 June 2013).

11. Harrington, D.R.; Khanna, M.; Deltas, G. Striving to be green: The adoption of total quality environmental management. Appl. Econ. 2008, 40, 2995-3007.

12. Khanna, M.; Deltas, G.; Ramirez Harrington, D. Adoption of pollution prevention techniques: The role of management systems and regulatory pressures. Environ. Resour. Econ. 2009, 44, 85-106.

13. Earnhart, D. Panel data analysis of regulatory factors shaping environmental performance. Rev. Econ. Stat. 2004, 86, 391-401.

14. Earnhart, D. Regulatory factors shaping environmental performance at publicly-owned treatment plants. J. Environ. Econ. Manag. 2004, 48, 655-681.

15. Gangadharan, L. Environmental compliance by firms in the manufacturing sector in Mexico. Ecol. Econ. 2006, 59, 477-486.

16. Sam, A.; Khanna, M.; Innes, R. Voluntary pollution reduction programs, environmental management, and environmental performance: An empirical study. Land Econ. 2009, 85, 692-711.

17. Johnstone, N.; Scapecchi, P.; Ytterhus, B.; Wolff, R. The firm, environmental management and environmental measures: Lessons from a survey of european manufacturing firms. J. Environ. Plan. Manag. 2004, 47, 685-707. 
18. Potoski, M.; Prakash, A. Covenants with weak swords: ISO 14001 and Facilities' environmental performance. J. Policy Anal. Manag. 2005, 24, 745-769.

19. Iraldo, F.; Testa, F.; Frey, M. Is an environmental management system able to influence environmental and competitive performance? The case of the eco-management and audit scheme (EMAS) in the european union. J. Clean. Prod. 2009, 17, 1444-1452.

20. King, A.; Lenox, M.; Terlaak, A. The strategic use of decentralized institutions: Exploring certification with the ISO 14001 management standard. Acad. Manag. J. 2005, 48, 1091-1106.

21. Rennings, K.; Ziegler, A.; Rehfeld, K. Integrated product policy and environmental product innovations: An empirical analysis. Ecol. Econ. 2007, 61, 91-100.

22. Ziegler, A.; Rennings, K. Determinants of Environmental Innovations in Germany: Do Organizational Measures Matter? A Discrete Choice Analysis at the Firm Level; ZEW Discussion Paper no. 04-30; Center for European Economic Research: Mannheim, Germany, 2004.

23. Potoski, M.; Prakash, A. Green clubs and voluntary governance: ISO 14001 and Firms' regulatory compliance. Am. J. Polit. Sci. 2005, 49, 235-248.

24. Sam, A. Impact of government-sponsored pollution prevention practices on environmental compliance and enforcement: Evidence from a sample of US manufacturing facilities. J. Regul. Econ. 2010, 37, 266-286.

25. Evans, M.; Liu, L.; Stafford, S. Do environmental audits improve long-term compliance? Evidence from manufacturing facilities in Michigan. J. Regul. Econ. 2011, 40, 279-302.

26. Khanna, M.; Widyawati, D. Fostering regulatory compliance: The role of environmental self-auditing and audit policies. Rev. Law Econ. 2011, 7, 129-163.

27. Khanna, M.; Anton, W.R.Q. Corporate Environmental management: Regulatory and market-based incentive. Land Econ. 2002, 78, 539-558.

28. Paxson, M.C. Response Rates for 183 Studies; Working Paper Washington State University; Washington State University: Washington, DC, USA, 1992.

29. Heckman, J. Sample selection bias as specification error. Econometrica 1979, 47, 153-161.

30. Sah, R. Social osmosis and patterns of crime. J. Polit. Econ. 1991, 99, 1272-1295.

31. Glicksman, R.; Earnhart, D. Depiction of the regulator-regulated entity relationship in the chemical industry: Deterrence-based V. Cooperative enforcement. William Mary Environ. Law Policy Rev. 2007, 31, 603-660.

32. Greene, W. Econometrics, 2nd ed.; Prentice Hall: Englewood Cliffs, NJ, USA, 1997.

33. Wooldridge, J. Econometric Analysis of Cross Section and Panel Data; MIT Press: Cambridge, MA, USA, 2002.

34. Greenstone, M. Estimating regulation-induced substitution: The effect of the clean air act on water and ground pollution. Am. Econ. Rev. 2003, 93, 442-448.

(C) 2013 by the authors; licensee MDPI, Basel, Switzerland. This article is an open access article distributed under the terms and conditions of the Creative Commons Attribution license (http://creativecommons.org/licenses/by/3.0/). 